\title{
BMJ Open How can we build and maintain the resilience of our health care professionals during COVID-19? Recommendations based on a scoping review
}

Anja Rieckert (1) , ${ }^{1,2}$ Ewoud Schuit, ${ }^{3,4}$ Nienke Bleijenberg, ${ }^{1,2}$ Debbie ten Cate, ${ }^{1,2}$ Wendela de Lange, ${ }^{3}$ Janneke M de Man-van Ginkel, ${ }^{1,2}$ Elke Mathijssen, ${ }^{3}$ Linda C Smit (1) ,2 Dewi Stalpers, ${ }^{1,5}$ Lisette Schoonhoven, ${ }^{1,6}$ Jessica D Veldhuizen (D) , ${ }^{2}$ Jaap CA Trappenburg ${ }^{1}$

To cite: Rieckert $A$, Schuit $E$, Bleijenberg N, et al. How can we build and maintain the resilience of our health care professionals during COVID-19? Recommendations based on a scoping review. BMJ Open 2021;11:e043718. doi:10.1136/ bmjopen-2020-043718

- Prepublication history and additional material for this paper is available online. To view these files, please visit the journal online (http://dx.doi.org/10. 1136/bmjopen-2020-043718)

Received 15 August 2020 Revised 19 November 2020 Accepted 27 November 2020

Check for updates

(C) Author(s) (or their employer(s)) 2021. Re-use permitted under CC BY-NC. No commercial re-use. See rights and permissions. Published by BMJ.

For numbered affiliations see end of article.

Correspondence to

Dr Anja Rieckert;

a.rieckert@umcutrecht.nl

\section{ABSTRACT}

Objective To explore how to build and maintain the resilience of frontline healthcare professionals exposed to COVID-19 outbreak working conditions.

Design Scoping review supplemented with expert interviews to validate the findings.

Setting Hospitals.

Methods We searched PubMed, Embase, PsycINF0, CINAHL, bioRxiv and medRxiv systematically and grey literature for articles focusing on the impact of COVID19-like working conditions on the physical and/or mental health of healthcare professionals in a hospital setting. Articles using an empirical design about determinants or causes of physical and/or mental health and about interventions, measures and policies to preserve physical and/or mental health were included. Four experts were interviewed to reflect on the results from the scoping review.

Results In total, 4471 records were screened leading to an inclusion of 73 articles. Recommendations prior to the outbreak fostering resilience included optimal provision of education and training, resilience training and interventions to create a feeling of being prepared. Recommendations during the outbreak consisted of (1) enhancing resilience by proper provision of information, psychosocial support and treatment (eg, create enabling conditions such as forming a psychosocial support team), monitoring the health status of professionals and using various forms and content of psychosocial support (eg, encouraging peer support, sharing and celebrating successes), (2) tasks and responsibilities, in which attention should be paid to kind of tasks, task mix and responsibilities as well as the intensity and weight of these tasks and (3) work patterns and working conditions. Findings of the review were validated by experts. Conclusions Recommendations were developed on how to build and maintain resilience of frontline healthcare professionals exposed to COVID-19 outbreak working conditions. These practical and easy to implement recommendations can be used by hospitals and other healthcare organisations to foster and preserve short-

\section{Strengths and limitations of this study}

- Combination of a scoping review based on a systematic literature search with expert interviews to foster evidence-based recommendations about how to keep healthcare professionals healthy and resilient during COVID-19 working conditions.

- An extensive overview of the current body of knowledge was provided by the extended search strategy, the inclusion of preprints and grey literature.

- The review process followed a universally agreed protocol (Preferred Reporting Items for Systematic Reviews and Meta-Analyses Extension for Scoping Reviews 2018) to ensure the quality of reporting.

- This study did not critically appraise the included articles and we cannot make conclusions regarding the quality of the evidence.

- Each outbreak has its own dimensions and each culture acts differently, which should be considered when interpreting the results.

term and long-term physical and mental health and employability of their professionals.

\section{INTRODUCTION}

Since it was first recognised in China in late 2019, COVID-19 has become a pandemic that continues to spread quickly around the world. By 17 November 2020, it has infected more than 55 million people worldwide and caused more than 11327253 deaths. ${ }^{1}$

The sudden massive outbreak of COVID-19 overwhelmed healthcare systems. Even the most resilient healthcare systems face insufficient treatment capacities due to the unexpected increase of often very ill patients with COVID-19. ${ }^{2}{ }^{3}$ Besides insufficient resources, 
this pandemic poses extreme pressures on healthcare professionals. $^{3}$

Experiences from previous similar outbreaks of infectious diseases, such as severe acute respiratory syndrome (SARS) (2003), middle east respiratory syndrome (MERS) (2013-2016) and Ebola (2014-2016) show that healthcare professionals are pushed to their limits in such situations. Each outbreak has its own dynamics, but they are all characterised by exposure to high workload, a shift in tasks and responsibilities, risk of infection, more difficult working conditions due to protective clothing and procedures, in addition to intense exposure to emotional events and trauma. ${ }^{4}$ Studies after the SARS, MERS and Ebola outbreaks show that, in the short term, persistent exposure to stress, anxiety, trauma/emotional events, sleep deprivation and fatigue lead to errors and decreased employability among healthcare professionals. Long-term effects include burn-out, depression and anxiety disorders as well as post-traumatic stress disorder. ${ }^{5-9} \mathrm{~A}$ variety of social and occupational factors affected the mental well-being, implying that it is important to take measures as early as possible to minimise harm. ${ }^{10}$

Early studies of and experiences with COVID-19 from China and Italy ${ }^{11-15}$ indicate that healthcare professionals face similar situations as encountered in previous outbreaks. The demand for care is increasing rapidly and care must be provided in stressful and uncertain circumstances causing emotional and physical exhaustion. ${ }^{16}$

A recent meta-analysis found a pooled prevalence of $23.2 \%$ for anxiety, $22.8 \%$ for depression and $38.9 \%$ for insomnia among healthcare professionals during the COVID-19 outbreak. ${ }^{17}$ As healthcare professionals are considered to be the 'most valuable resource', maintaining mental and physical health for the short and long term, and hence the employability of healthcare professionals, is essential in coping with what is expected to be a long-term COVID-19 outbreak. Several international organisations, such as the WHO, have developed documents providing recommendations to improve mental well-being of healthcare professionals during this COVID-19 outbreak. ${ }^{18-20}$

Furthermore, two systematic reviews investigated the psychological well-being of healthcare professionals involved in SARS. Brooks $e t a l^{10}$ concluded the importance of preparing healthcare professionals for the potential psychological impact, to stimulate a supportive working environment and to ensure provision of support for those who need it. Koh $e t a l^{21}$ advise to empower healthcare professionals through education and training, to provide safe environments and to offer incentives to those who are exposed to extra high risks.

However, to our knowledge, there has been no attempt to systematically summarise the evidence on improving and maintaining healthcare professionals' resilience generated from several similar outbreaks. As COVID-19 is a new disease, we decided to have a broad scope and also explored what we can learn from previous similar virus outbreaks in the 21st century such as SARS, MERS and
Ebola. These viruses have in common that they all are fast-spreading viruses impacting entire communities. ${ }^{22}$ Given the urgency of the COVID-19 outbreak, we felt the need to rapidly synthesise the evidence and to produce practical recommendations, which can be implemented in a quick and easy way.

\section{METHODS}

In this study, a scoping review was conducted and filled with information provided by expert interviews. Given the broad scope of the research aim, expected heterogeneity of the body of evidence and urgency to get results, ${ }^{23-27}$ a scoping review was conducted without the use of a formal protocol. The scoping review is reported according to the Preferred Reporting Items for Systematic Reviews and Meta-Analyses extension for Scoping Reviews (PRISMA-ScR) ${ }^{28}$

\section{Identification of articles}

The databases PubMed, Embase, PsycINFO, CINAHL, bioRxiv and medRxiv were systematically searched for (prepublished) literature on interventions and measures for the preservation of short-term and long-term physical and/or mental health and employability of healthcare professionals exposed to epidemic/pandemic outbreak working conditions, published between January 2003 and March 2020. Epidemic/pandemic outbreaks of interest include SARS (2003), MERS (2013-2016), Ebola (20142016) and COVID-19. Because the SARS outbreak took place in 2003, we used this year as a starting point for our search. The full search strategies were developed in collaboration with a medical librarian from Utrecht University and further refined through team discussion (see online supplemental appendix 1). Additionally, the grey literature was searched with a focus on leading organisations with expertise in outbreak situations, including the WHO, Médecins Sans Frontières, The International Committee of the Red Cross, United Nations, International Council of Nurses and the Dutch Ministry of Defense. Healthcare professionals were defined as 'a person associated with either a specialty or a discipline and who is qualified and allowed by regulatory bodies to provide a healthcare service to a patient' ${ }^{29}$ Resilience is typically defined as the 'successful adaptation to adversity', entailing the concept of recovery, that is, 'how well do people bounce back and recover fully from challenge' and sustainability, that is, 'the capacity to continue forward in the face of adversity ${ }^{30}$ We chose a multifaceted approach to resilience, ${ }^{31}$ not only recognising the role of the individual but also personal, social and workplace features. ${ }^{32} 33$

\section{Selection of articles and data extraction}

Peer-reviewed and preprint articles were included when they concerned empirical research (both original articles and reviews) and focused on COVID-19 and other outbreak-related working conditions on the shortterm and long-term physical and/or mental health and 
employability of healthcare professionals. Research on predictors or causes of physical and/or mental health as well as research into interventions, measures and policies to preserve physical and/or mental health were included. Articles written in a language other than English or Dutch were excluded. Articles were screened on title and abstract by pairs of independent reviewers (AR, DS, DtC, EM, ES, JCAT, JDV, LCS, NB, WdL). Discrepancies were resolved by a third reviewer (LCS, WdL).

The full-text assessment and data extraction were performed by one reviewer per article (AR, DS, DtC, EM, JMdM-vG, JDV, LCS, NB, JCAT, WdL) and subsequently checked for accuracy by a second reviewer (AR, DtC, EM, JMdM-vG, JDV, LCS). Data extraction was performed using a standardised form with which data were extracted regarding the first author, year of publication, location, target population, type of disease outbreak, type of study, $\operatorname{method}(\mathrm{s})$ of data collection, interventions/measures, recommendations regarding the use of the intervention/ measure, timing of the intervention/measure (before or during the outbreak) and purpose of the intervention/measure. The process of data extraction with the standardised form was piloted on four studies, by two reviewers (DtC and LCS).

\section{Data extraction and development of recommendations}

A matrix was drawn up for data extraction that would allow for summarising recommendations based on the timing of the interventions/measures (before or during the outbreak) and the specific topics: resilience, tasks and responsibilities and working conditions.

The matrix was constructed based on a rough exploration of the literature and was further refined through team discussion, interviewing experts (see below) and was adapted iteratively based on the findings of the included studies. Per article, one reviewer (ES, EM, DS, DtC, JMdMvG, JDV, LCS, NB) narratively synthesised data regarding interventions/measures for each topic. This synthesis was then checked by a second reviewer. The findings of the scoping review were triangulated with the findings of the expert interviews (see next paragraph) and subsequently practical recommendations regarding the preservation of short-term and long-term physical and/or mental health and employability of healthcare professionals exposed to COVID-19 and other outbreak-related working conditions were formulated. The quality of evidence was not considered when formulating recommendations. Two reviewers (JCAT, LS) checked the recommendations for accuracy. The recommendations turned out to be on environmental, individual and organisational levels. Thus, when presenting the results, we indicate the level.

\section{Expert interviews}

Parallel to the scoping review, four experts were recruited for a semistructured interview based on a purposive sampling method. Two experts were selected based on their expertise (psychological trauma and prevention and treatment of psychological disorders following trauma).
One of the experts recommended another expert based on her expertise with supporting healthcare professionals after traumatic events or difficult work situations. The fourth expert was recommended by one of the researchers (JCAT) based on her expertise (integrity and resilience in law enforcement training and practice). The experts were asked to evaluate the data synthesis matrix (completeness and importance of the topics, additions based on their expertise). The interviews were conducted by telephone, audio-recorded and subsequently summarised. In addition to the interviews, the experts received a draft of the recommendations once the data synthesis was completed. Some content-related additions were made accordingly.

\section{Patient and public involvement}

This study was planned in collaboration with the University Medical Hospital Utrecht. This study was conducted for and by healthcare professionals (mostly nurses). Some of them worked in a COVID-19 ward or intensive care unit during the COVID-19 outbreak. Additionally, various experts were involved in the validation of the findings. Two frontline nurses, working at the COVID-19 unit or the intensive care unit, were asked to review our recommendations and comment on the fit of the recommendations with their daily work circumstances.

\section{RESULTS}

\section{Scoping review}

Study selection

The literature search identified 6054 articles. After removing duplicates, 4471 articles remained. Based on the screening of title and abstract, 4318 articles were excluded. The full texts of the remaining 158 articles were assessed for eligibility, which resulted in the inclusion of 73 articles reporting on 71 unique studies (see figure 1 for the selection process). Two studies were both reported in two articles. ${ }^{54-36}$ In addition, we considered five articles from the grey literature as relevant. These articles were reports by international organisations rather than empirical studies.

\section{Study characteristics}

Studies were conducted in a variety of countries between 2003 and 2020 (see table 1). They referred to an outbreak of MERS $(n=11)$, SARS $(n=36)$, Ebola $(n=13)$ or COVID-19 (n=9). Two studies did not refer to a specific disease outbreak or referred to various disease outbreaks. Studies used qualitative methods $(\mathrm{n}=21)$, quantitative methods $(n=43)$ or mixed-methods $(n=4)$. Two were systematic reviews and one a focused review. See table 2 for detailed study characteristics.

\section{Expert interviews}

Interviews were conducted in March 2020 with four experts: a professor and chair of psychological trauma, a senior researcher in the field of prevention and treatment of psychological disorders following trauma, a 


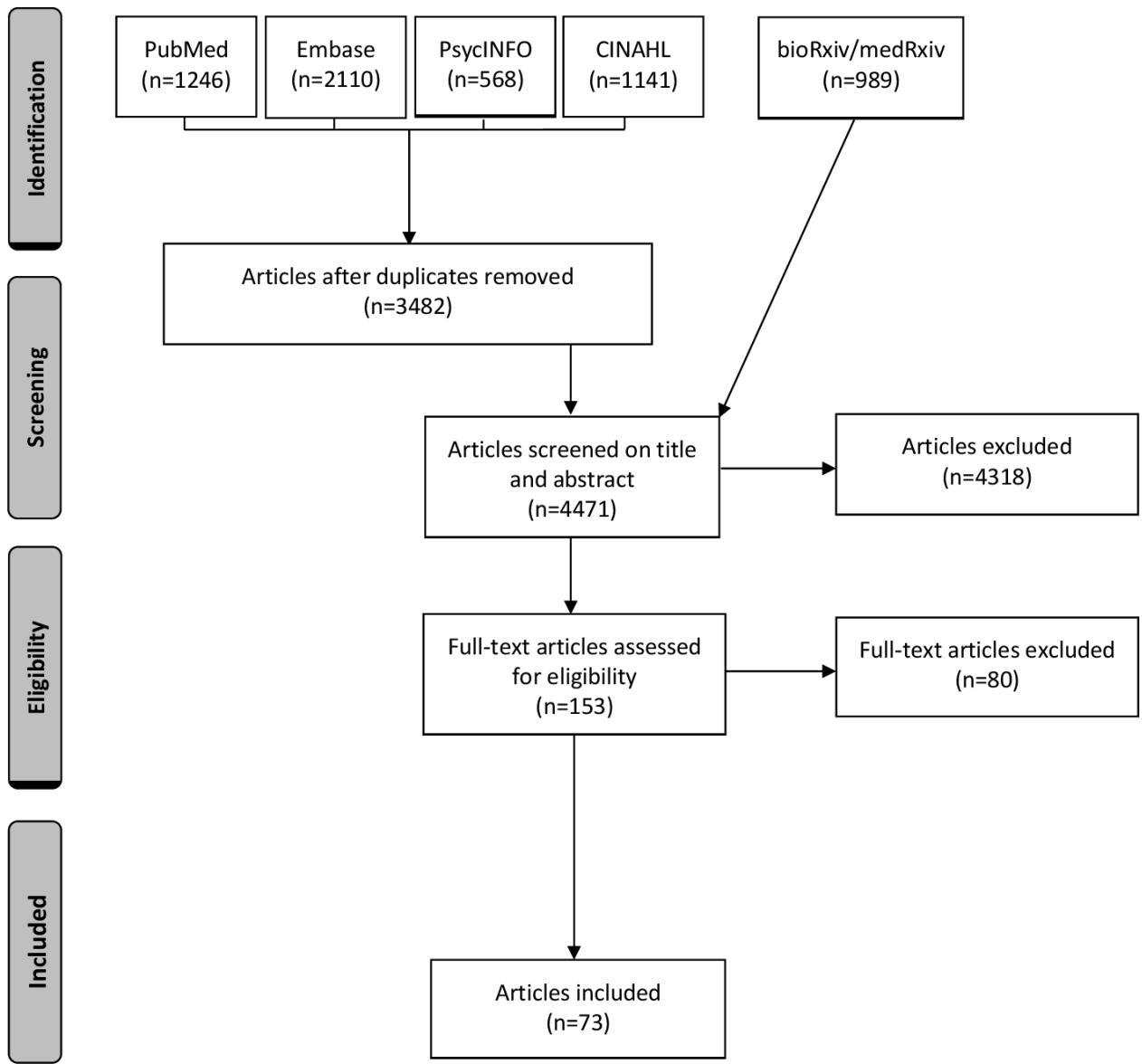

Figure 1 Flow diagram of the selection process.

senior researcher in the field of integrity and resilience in law enforcement training and practice and a trauma coordinator at a general hospital. Interviews lasted between half an hour and $45 \mathrm{~min}$.

\begin{tabular}{|c|c|}
\hline Country & Number of studies \\
\hline Canada & 13 \\
\hline China & 16 \\
\hline $\begin{array}{l}\text { Congo-Kinshasa, Congo-Brazzaville } \\
\text { and Uganda }\end{array}$ & 1 \\
\hline Germany & 1 \\
\hline Japan & 1 \\
\hline Liberia & 2 \\
\hline Saudi Arabia & 5 \\
\hline Sierra Leone & 3 \\
\hline Singapore & 4 \\
\hline South Korea & 6 \\
\hline Spain & 1 \\
\hline Taiwan & 10 \\
\hline The Netherlands & 1 \\
\hline USA & 4 \\
\hline Various & 3 \\
\hline
\end{tabular}

\section{Practical recommendations}

Results of the data extraction are presented in online supplemental appendix 1. Below a range of the developed practical recommendations are depicted.

Before the outbreak

\section{Resilience}

Three intervention components prior to or in the run-up to the outbreak were found regarding the concept of resilience: (1) education and training, (2) resilience training and (3) perception of preparedness.

\section{Education and training — organisational level}

Several studies recommended to provide information and education to healthcare professionals about the virus, method of transmission, symptoms and protective measures. This information should be up to date and be clearly communicated..$^{34} 3537$ Furthermore, many studies found it essential to train professionals in recognising symptoms, in preventing transmission and in using protective measures and associated procedures. ${ }^{10} 10343539-43$

\section{Resilience training —organisational level}

Resilience training, moral and psychological support to healthcare professionals from outside and within the healthcare teams that provide direct (daily) patient care should be provided. ${ }^{44-47}$ Professionals should be 

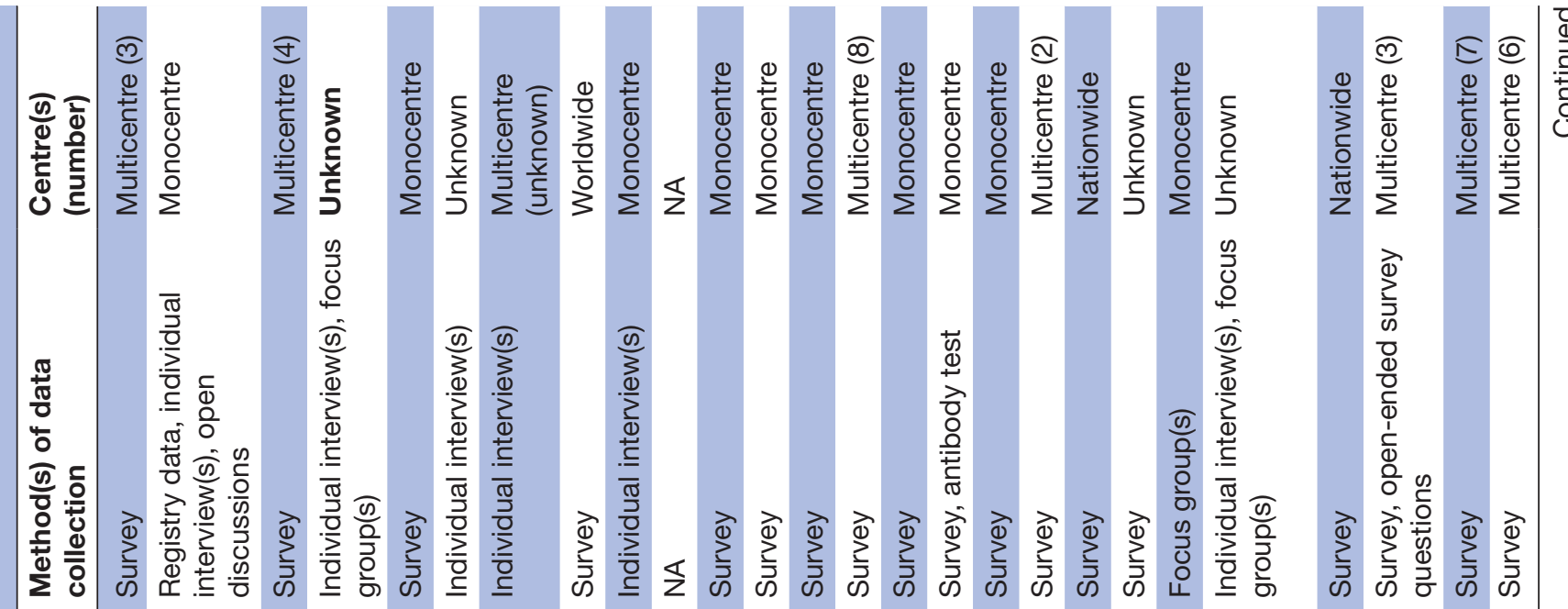

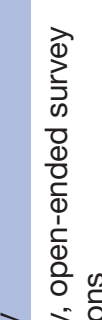

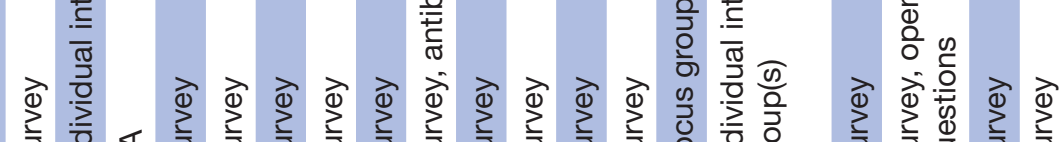

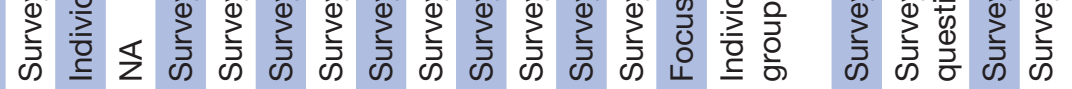

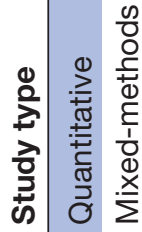

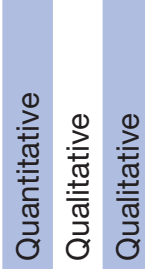

:

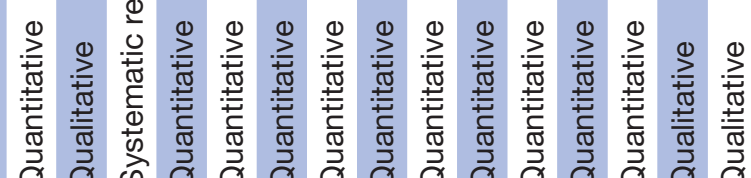

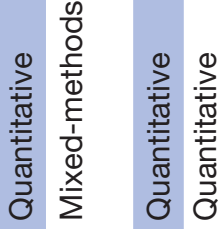

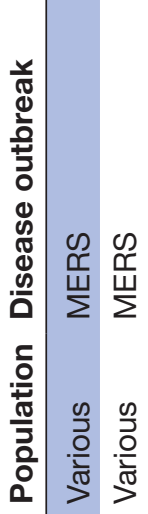

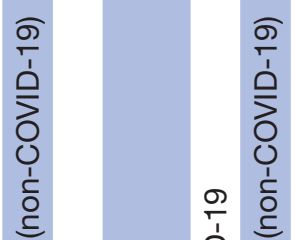

ค

क

仓่

ठ ठ

일

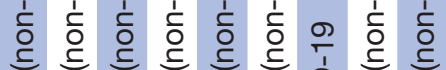

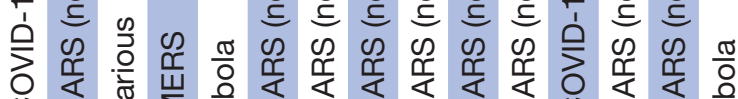

a)

क क

$\stackrel{8}{>} \stackrel{8}{8}$

ठ

든

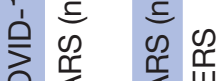

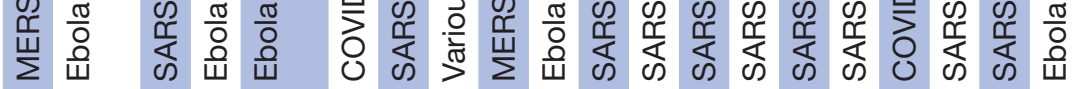

ठठ

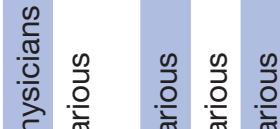

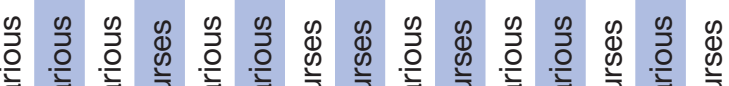

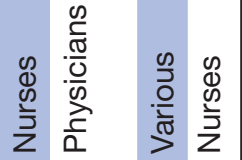

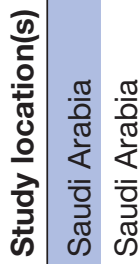

$>$

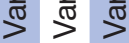

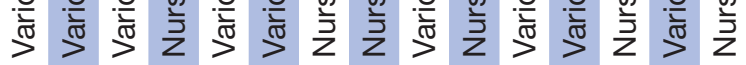

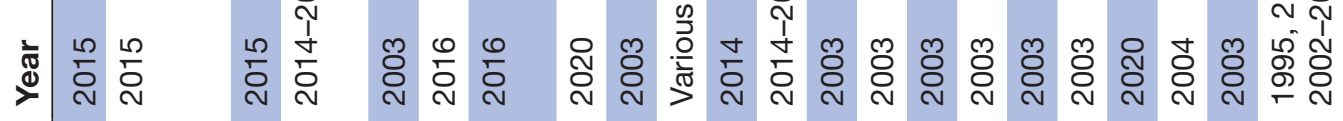

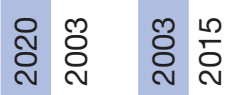




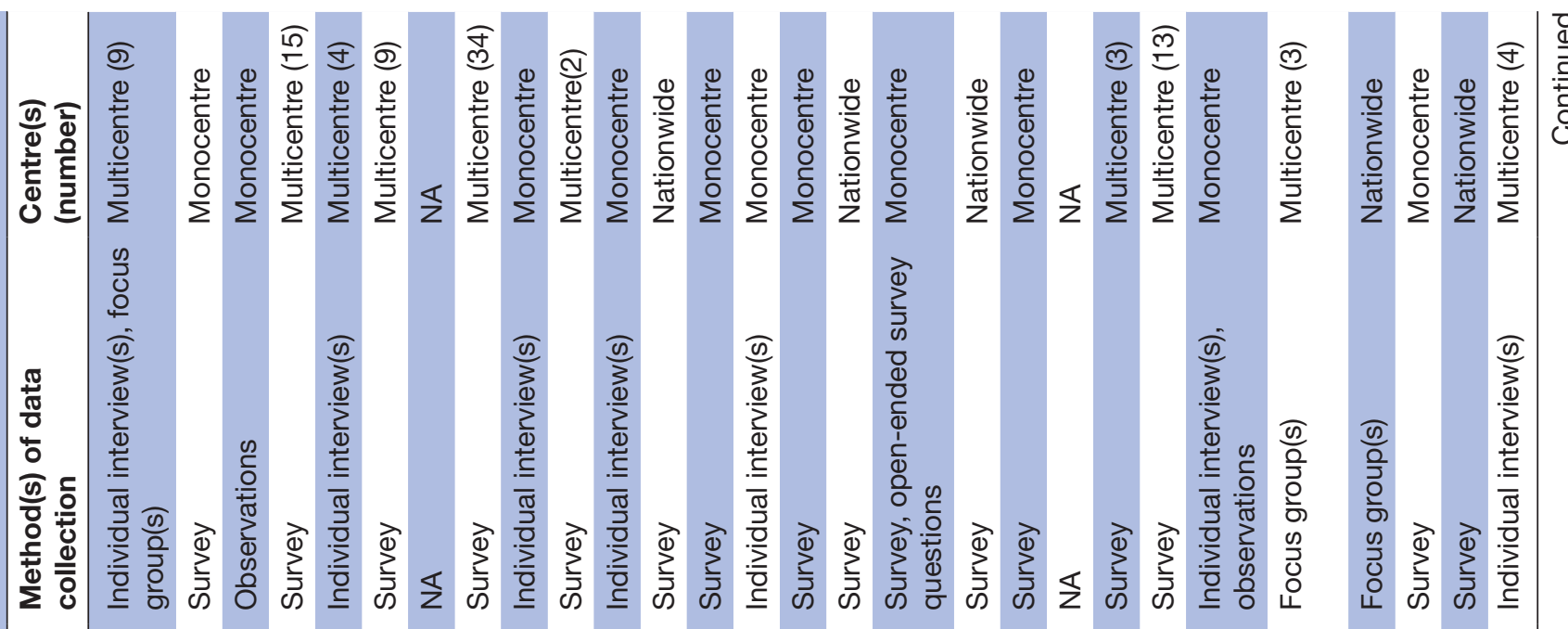

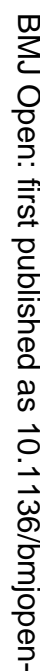

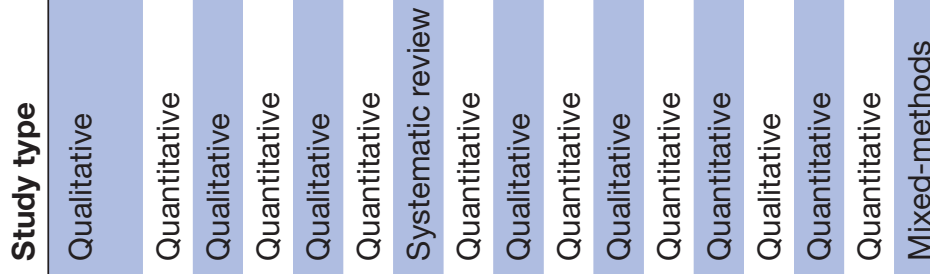

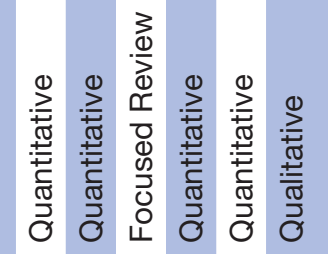

$\frac{0}{0}$

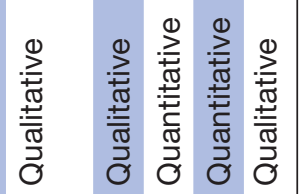

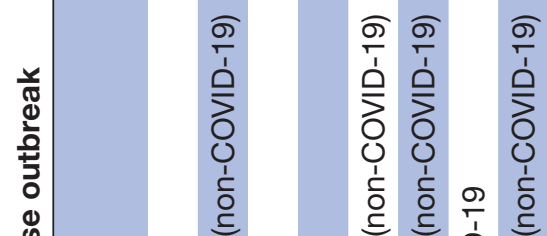
б ब

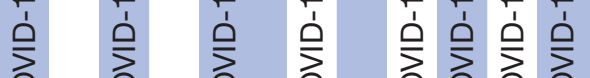

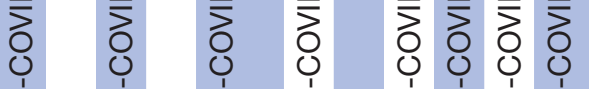

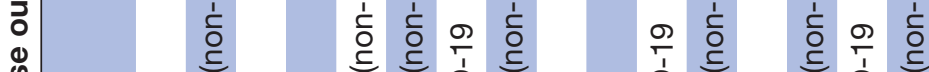

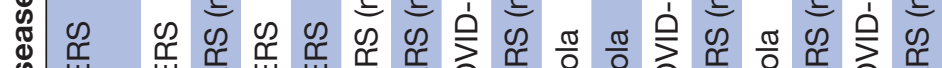

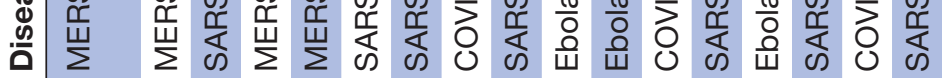
竞

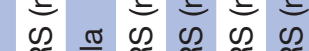

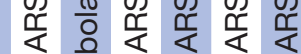

들

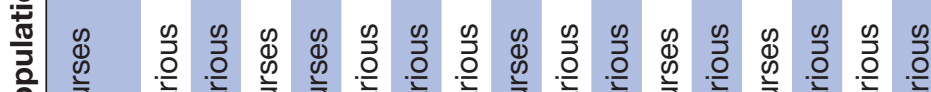

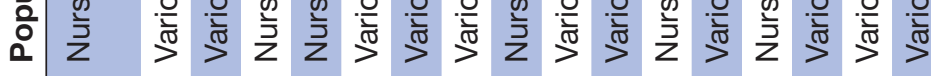

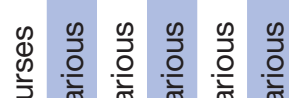

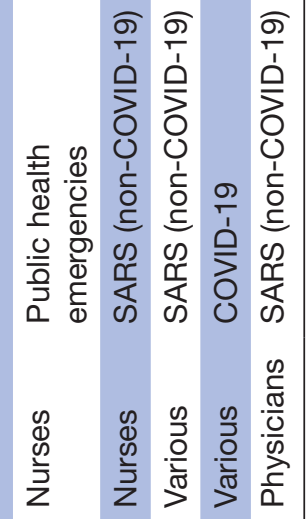

क्ञ 营

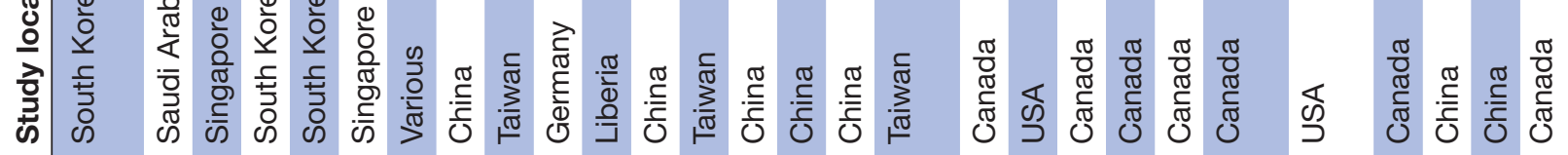
กิ 离

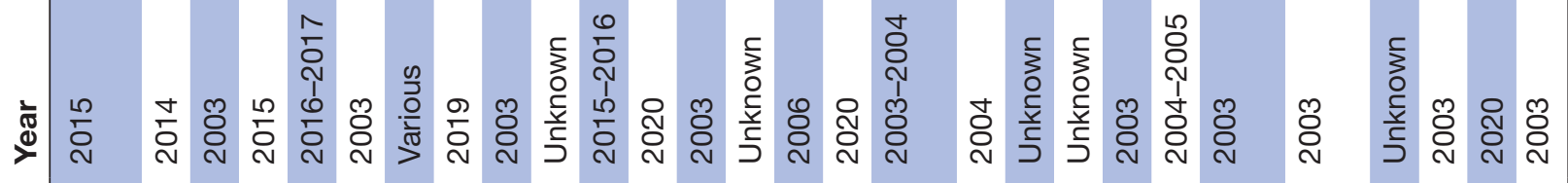

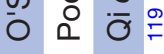




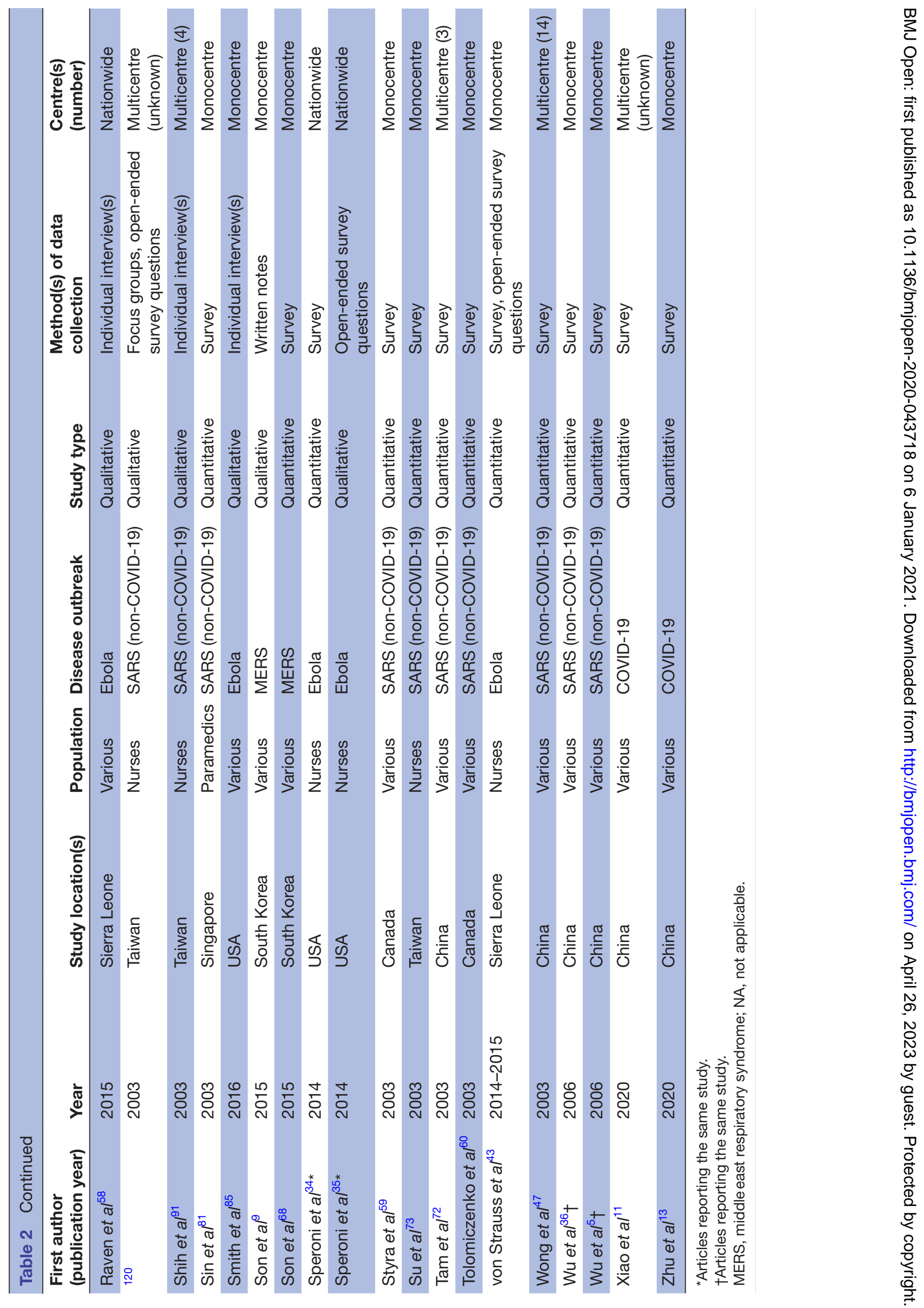


informed about the psychosocial risks of working in outbreak situations and be trained on how to deal with isolation, stigmatisation, fatigue, stress and feelings of depression. ${ }^{10374849}$ The expert interviews added that this training should also be targeted at managers. Besides, Marrs et a $t^{49}$ recommended training on interprofessional teamwork.

\section{Perception of preparedness_-organisational level}

To maximise perception of preparedness, protocols should be up to date, a clear action plan should be made and effective communication strategies be implemented. The hospital or organisation must ensure that sufficient staff and materials are available to handle the outbreak. A safe work environment should be promoted, for example, minimal movements of heavy materials, enough space to work and keep distance and locks between high-risk and low-risk patients. ${ }^{50}$ Besides, involving the staff in the preparations for the planning of the upcoming demand of care is recommended. ${ }^{404651}$ Attention should be paid to potential ethical dilemmas in healthcare and the intensity of care. These dilemmas can for instance include not being able to provide good care or feeling obliged to do the job even if it is not possible. ${ }^{536434652}$

\section{During the outbreak \\ Resilience}

During the outbreak, some interventions were also related to the concept of resilience: (1) communication, (2) psychosocial support and treatment, (3) monitoring health status.

\section{Communication — organisational, individual and environmental level}

One person within each healthcare team should be responsible for grouping information. ${ }^{38505354}$ Realistic scenarios or actual scenarios should be discussed within a healthcare team that provides direct (daily) patient care. ${ }^{505354}$ It is recommended to create a blame-free environment in which frontline professionals are provided the ability to report incidents, ethical or emergency issues, challenges and advice for management. ${ }^{37} 5055 \mathrm{~A}$ platform on which healthcare professionals can share information, experiences and good practices for communication among peers and with collaborating parties should be offered. ${ }^{56-59}$ Furthermore, involving nursing staff in the decision-making processes (also at management level) has been recommended as this group is often neglected. Having short communication lines between professionals is important. ${ }^{960}$

\section{Psychosocial support and treatment: create enabling conditions- organisational level}

It is important to create enabling conditions early on in the outbreak for optimal professional psychosocial support for healthcare professionals both within regular care and in acute situations. ${ }^{11} 121453$ These facilities should be accessible for all healthcare professionals and this should be clearly communicated. Furthermore, there should be sufficient resources/capacity for a multidisciplinary psychosocial support team consisting of peer support, psychologists, spiritual counsellors, social professionals, occupational health and safety physicians. ${ }^{53}$ It is recommended to create a simple and agile organisational structure for the psychosocial support team. There should be a clear functional and hierarchical management of and communication towards as well as within the operational core. For example, making a $24 / 7$ telephone number by members of the psychosocial support team available to professionals who are in need to talk to someone. ${ }^{7}$ Furthermore, it is recommended to create an efficient referral system for professionals with physical or psychological problems so that they can obtain a diagnosis quickly and professional treatment if indicated. ${ }^{42}$ Sufficient professional psychosocial capacity during the peak of the outbreak is needed and financial compensation for the treatment needs to be ensured. ${ }^{9}{ }^{4661-68}$ It is beneficial to identify professionals who are at high risk of psychosocial problems early. Special attention should be paid to frontline professionals, professionals in quarantine, women, young/inexperienced and conversely older professionals. ${ }^{5467}$

\section{Form and content of psychosocial support—organisational and} environmental level

Many of the included studies encouraged communication between professionals in the workplace, even during busy periods and create time for non-binding discussion of positive and negative aspects of the situation. $^{384750626769-71}$ Communication should make use of natural coping strategies (acceptance, active coping, positive framing) rather than the broad use of psychological interventions such as therapy. ${ }^{5} 7363846475264$ When professionals suffer from complaints in acute situations, it is recommended to offer evidence-based interventions following a formal diagnosis and treatment process by professionals who are not involved in the workplace. ${ }^{9}{ }^{46} 61-68$ Furthermore, hospitals should offer professionals the opportunity to quickly withdraw from an emotionally stressful situation ${ }^{37}$ by creating a safe area where professionals can catch their breath or blow off steam and get peer support. Opportunities to stay in direct or indirect contact with family and friends should be created..$^{52637172}$

\section{Monitoring health status of professionals_-organisational level}

It is important to constantly be aware of the mental or physical health of professionals and to scale up monitoring when problems increase and/or the outbreak persists. ${ }^{13}$ Besides, frequent but casual monitoring of the physical and mental health status aiming at early identification of the problems is needed. A daily check-in/ check-out is an excellent low-threshold method to gauge how someone is doing, whether there are concerns, and if something is bothering someone. ${ }^{13} 73$ 
Tasks and responsibilities

Intensity of tasks and responsibilities—organisational level

A good care provider-patient ratio is crucial meaning that the care-related workload is in proportion to the care providers' capacity since it safeguards safety and quality of care. ${ }^{55}$

\section{Work pattern and working conditions}

Work pattern—organisational level

Limiting shifts to a maximum of 12 hours shifts with light tasks $^{50}$ or $8-10$ hours for shifts within intense tasks ${ }^{42}$ are recommended. For evening and night shifts 8 hours are indicated ${ }^{50}$ A series of shifts should be followed by days off, ${ }^{375054}$ which should be scheduled often enough (which also applies for breaks)..$^{5074}$ More specifically, after a series of 8-10-hour shifts, at least 1 or 2 days off should be scheduled. ${ }^{50}$ Days off and vacation should also be planned during an outbreak ${ }^{38} 5675$ and healthcare professionals should not be approached with work-related information and/or questions when not at work.

Working on the frontline should be limited to 6-8 weeks. These frontline shifts should be alternated with nonfrontline shifts. ${ }^{38}$ To ensure healthy work patterns, it is recommended to deploy managers as role models ${ }^{7}$ and review and evaluate the division of labour and planning and the strict adherence to the working hours. ${ }^{567717677}$

\section{Team composition—organisational and individual level}

Deploying full-time professionals wherever possible enhances the continuity of care. ${ }^{78}$ Shifting professionals who held non-essential positions before the outbreak to essential positions should be done only after adequate training. ${ }^{50}$ Several studies highlighted the benefits of setting up a buddy system in which two professionals are linked together during a shift. ${ }^{37-39} 46505359647980$ Furthermore, it is recommended that there is always someone with whom professionals can talk before, during and after their shift and with whom they can unload. ${ }^{1157628182}$

\section{Team building —organisational and individual level}

Many of the included studies recommended to improve the atmosphere in the department by creating a sense of togetherness and positivity. Everyone should feel that their voice is heard. ${ }^{79} 10435768747882-86$

\section{Respect the autonomy—organisational level}

It is widely agreed that the autonomy of healthcare professionals should be respected. They should have a choice of whether or not to work with patients with COVID-19 and should notbejudged on their choice. ${ }^{34355254647287}$ If healthcare professionals develop complaints while working, they should be given the choice to perform other activities elsewhere (expert interview).

\section{Rooms and facilities-environmental level}

Ideally, each department should have a separate room available for professionals to retreat, rest or sleep. 7385053707176808889 Time, space and opportunities should be offered to let professionals exercise individually or jointly and/or perform (relaxing) activities. Exercise can serve as an outlet to reduce stress. ${ }^{3850} 89$

\section{Availability of materials—organisational level}

It is essential to provide healthcare professionals, especially those on the frontline, with adequate materials $^{793435526468747980}$. Besides, training in and supervision of correct use of personal protective equipment are needed. ${ }^{93767687380868790}$ It is recommended not to share concerns about lack of materials with all professionals in the department. ${ }^{7280}$ The expert interviews added that one person should be assigned the responsibility to further inventor the availability and to take any action to resolve shortages.

\section{Compensation—organisational level}

It is recommended to offer (frontline) professionals' compensation for practical support, in relation to extraordinary tasks, responsibilities and risks. ${ }^{42} 586472808491$ Additionally, social services such as child or animal care or care for the elderly should be provided to the next of kin/family of the (frontline) professionals. ${ }^{79}$ It should be ensured that staff have a good living environment at home, so that sufficient relaxation and sleep can be achieved. ${ }^{38} 5061$

\section{Possibility to eat and drink—organisational level}

It is recommended to offer professionals, especially those in the frontline, sufficient and easy accessible high nutritional food and drinks during every shift. ${ }^{3842} 506480$ Working in protective clothing considerably reduces the possibility of eating. As frontline professionals should take as much rest as possible during their time off, they should not be worried about preparing a balanced diet at home and to work. ${ }^{742} 71$

\section{DISCUSSION}

This study presents practical recommendations on how to build and maintain the resilience among frontline healthcare professionals exposed to COVID-19 and other outbreak-related working conditions based on a scoping review and expert interviews. These recommendations encompass a variety of small and large interventions prior to the outbreak as well as during the outbreak. Recommendations prior to the outbreak fostering resilience included optimal provision of education and training, resilience training and interventions to create a feeling of being prepared. Recommendations during the outbreak consisted of (1) enhancing resilience by proper provision of information, psychosocial support and treatment, monitoring the health status of professionals and using various forms and contents of psychosocial support, (2) tasks and responsibilities, in which attention should be paid to kind of tasks, task mix and responsibilities as well as the intensity and weight of these tasks and (3) work patterns and working conditions. 


\section{Strengths and limitations}

To our knowledge, this is the first study that combined a scoping review based on a systematic literature search with expert interviews to foster evidence-based recommendations about how to keep healthcare professionals healthy and resilient during COVID-19 working conditions. Due to the COVID-19 outbreak and the urgent need for scientific research, no study protocol was published in advance. However, the unpublished protocol is available from the corresponding author on request. Yet, an extensive overview of the current body of knowledge was provided by the extended search strategy, the consideration of preprints and grey literature.

The review process followed a universally agreed protocol (PRISMA Extension for Scoping Reviews 2018) to ensure the quality of reporting. ${ }^{28}$ However, this study did not critically appraise the included articles and we cannot make conclusions regarding the quality of the evidence. $^{9293}$ The data collection and data management processes were thorough as all phases of the scoping review were checked by a second reviewer and when necessary a third reviewer. The synthesis of the results was approved by all 12 authors to ensure the validity of the findings. Additionally, the expert interviews increased the trustworthiness of the data.

Most studies included in this review were conducted during or after previous outbreaks that were similar to COVID-19. However, each outbreak has its own dimensions and each culture acts differently. This holds especially true for the Ebola outbreak in Africa, which was included in this review. Hence, care might have been carried out in other ways, due to differences in disease transmission, culture and the healthcare system. Though we consider this literature to be relevant, this should be considered when interpreting the results.

\section{Comparison with other studies}

The literature of the impact of the COVID-19 outbreak on healthcare professionals is currently expanding rapidly especially on the impact of changed patient care on the involved healthcare professionals. ${ }^{94-96}$ Furthermore, predictors for mental health problems of healthcare professionals during the COVID-19 outbreak accompanied by suggestions of global and small interventions to implement rapidly. ${ }^{97-100}$ In most studies, only a particular aspect of mental health problems was explored such as anxiety, burnout and fatigue or psychological (dis) stress. ${ }^{101-103}$

Enhancement of resilience by proper provision and receiving of information and by providing psychosocial support and treatment embedded in a safe and blame-free (working) environment is also emphasised by De Brier $e t$ $a l \mathrm{~s}^{99}$ rapid systematic review on mental health support during outbreaks. Reducing other tasks to allow healthcare professionals to focus on the immediate needs ${ }^{3}$ is in line with our findings. Research prior to the COVID-19 outbreak showed that occupational factors such as shift work, hours worked and job strain led to depression and burnout. ${ }^{104-106}$ Work conditions as a lack of breaks during shifts have been associated with nurses' fatigue. Fatigue can directly affect the physical health of professionals by increasing risk of injuries. ${ }^{107} 108$ Breaks to rest are important for managing fatigue and improving shortterm performance. ${ }^{109-112}$ The sudden massive outbreak of COVID-19 that overwhelmed healthcare systems will further magnify these occupational factors if no attention is paid to healthcare professionals. ${ }^{3}$

COVID-19 is a new disease outbreak, we so far have only limited knowledge about. Some of our recommendations as providing good information and clarity were at the begin of the outbreak rather difficult to put into practice. Especially the shortage of protective material in many countries caused great unrest. In a second wave, it should be ensured that this will be better regulated.

\section{Implications}

These practical recommendations provide an overview of possible interventions that can be implemented in clinical practice to reduce the burden of healthcare professionals exposed to COVID-19 working conditions and may prevent and reduce possible negative consequences. Government should provide healthcare organisations with sufficient resources to implement these recommendations that fit their needs and adapt them to their context. Recommendations were targeted at various levels: from senior management to healthcare professionals. Even though the recommendations were primarily developed for hospitals, many are transferable to other settings as well. To enhance the evidence base of the recommendations, evaluating the effectiveness of the above-mentioned recommendations during COVID-19 working conditions should be stimulated.

\section{CONCLUSION}

Healthcare professionals should be supported in various ways during the extreme COVID-19 working conditions to prevent and reduce possible negative consequences. Many practical and easy to implement recommendations were created to foster physical and mental health of healthcare professionals. Hospitals (and other healthcare organisations) should stimulate the implementation of interventions mentioned in these recommendations at various levels in their organisations.

\section{Author affiliations}

${ }^{1}$ Nursing Science, Julius Center for Health Sciences and Primary Care, University Medical Center Utrecht, Utrecht University, Utrecht, The Netherlands

${ }^{2}$ Research Group Chronically III, Research Centre for Healthy and Sustainable Living, University of Applied Sciences Utrecht, Utrecht, The Netherlands

${ }^{3}$ Julius Center for Health Sciences and Primary Care, University Medical Center Utrecht, Utrecht University, Utrecht, The Netherlands

${ }^{4}$ Cochrane Netherlands, University Medical Center Utrecht, Utrecht University, Utrecht, Netherlands

${ }^{5}$ Dutch Hospital Association, Utrecht, Netherlands

${ }^{6}$ School of Health Sciences, Faculty of Environmental and Life Sciences, University of Southampton, Southampton, UK 
Twitter Jessica D Veldhuizen @jdpoortv

Acknowledgements We would like to express our gratitude to all experts participating in the interviews

Contributors JCAT, LS, JDV, AR, NB, WdL, EM, JMdM-vG and ES conceptualised this study. AR, DS, DtC, EM, ES, JMdM-vG, JCAT, JDV, LS, NB and WdL conducted the scoping review. WdL conducted the expert interviews. LS checked the recommendations and provided overall guidance. AR, EM, ES, LS and NB conceptualised this manuscript. All authors critically read and approved the final manuscript. The corresponding author attests that all listed authors meet authorship criteria and that no others meeting the criteria have been omitted. The corresponding author acts as the guarantor.

Funding The authors have not declared a specific grant for this research from any funding agency in the public, commercial or not-for-profit sectors.

Transparency declaration The lead author (the manuscript's guarantor) affirms that the manuscript is an honest, accurate and transparent account of the study being reported; that no important aspects of the study have been omitted; and that any discrepancies from the study as planned (and, if relevant, registered) have been explained.

Competing interests None declared.

Patient consent for publication Not required.

Ethics approval No ethical approval was needed. All experts participating at the interviews provided prior verbal informed consent.

Provenance and peer review Not commissioned; externally peer reviewed.

Data availability statement Data sharing not applicable as no datasets generated and/or analysed for this study. Data are available upon reasonable request. All data of this study will be provided upon reasonable request from the corresponding author at a.rieckert@umcutrecht.nl.

Supplemental material This content has been supplied by the author(s). It has not been vetted by BMJ Publishing Group Limited (BMJ) and may not have been peer-reviewed. Any opinions or recommendations discussed are solely those of the author(s) and are not endorsed by BMJ. BMJ disclaims all liability and responsibility arising from any reliance placed on the content. Where the content includes any translated material, BMJ does not warrant the accuracy and reliability of the translations (including but not limited to local regulations, clinical guidelines, terminology, drug names and drug dosages), and is not responsible for any error and/or omissions arising from translation and adaptation or otherwise.

Open access This is an open access article distributed in accordance with the Creative Commons Attribution Non Commercial (CC BY-NC 4.0) license, which permits others to distribute, remix, adapt, build upon this work non-commercially, and license their derivative works on different terms, provided the original work is properly cited, appropriate credit is given, any changes made indicated, and the use is non-commercial. See: http://creativecommons.org/licenses/by-nc/4.0/.

\section{ORCID iDs}

Anja Rieckert http://orcid.org/0000-0002-9735-378X

Linda C Smit http://orcid.org/0000-0001-5488-2967

Jessica D Veldhuizen http://orcid.org/0000-0002-7761-5690

\section{REFERENCES}

1 John Hopkins University. COVID-19 dashboard by the center for systems science and engineering [Internet]. Global map coronavirus resource center, 2020. Available: https://coronavirus.jhu.edu/map. htm

2 World Health Organization. Strategic preparedness and response plan for the new coronavirus, 2020. Available: https://www.who.int/ publications-detail/strategic-preparedness-and-response-plan-forthe-new-coronavirus

3 Adams JG, Walls RM. Supporting the health care workforce during the COVID-19 global epidemic. JAMA 2020;323:1439-40.

4 Maunder RG, Leszcz M, Savage D, et al. Applying the lessons of SARS to pandemic influenza. Can J Public Health 2008;99:486-8.

5 Wu P, Fang Y, Guan Z, et al. The psychological impact of the SARS epidemic on hospital employees in China: exposure, risk perception, and altruistic acceptance of risk. Can J Psychiatry 2009;54:302-11.

6 Koh D, Lim MK, Chia SE, et al. Risk perception and impact of severe acute respiratory syndrome (SARS) on work and personal lives of healthcare workers in Singapore. Med Care 2005;43:676-82.

7 Maunder R, Hunter J, Vincent L, et al. The immediate psychological and occupational impact of the 2003 SARS outbreak in a teaching hospital. CMAJ 2003;168:1245-51.

8 McAlonan GM, Lee AM, Cheung V, et al. Immediate and sustained psychological impact of an emerging infectious disease outbreak on health care workers. Can J Psychiatry 2007;52:241-7.

9 Son H, Lee WJ, Kim HS, et al. Examination of hospital workers' emotional responses to an infectious disease outbreak: lessons from the 2015 MERS Co-V outbreak in South Korea. Disaster Med Public Health Prep 2019;13:504-10.

10 Brooks SK, Dunn R, Amlôt R, AmlA't R, et al. A systematic, thematic review of social and occupational factors associated with psychological outcomes in healthcare employees during an infectious disease outbreak. J Occup Environ Med 2018;60:248-57

11 Xiao $\mathrm{H}$, Zhang $\mathrm{Y}$, Kong D, et al. The effects of social support on sleep quality of medical staff treating patients with coronavirus disease 2019 (COVID-19) in January and February 2020 in China. Med Sci Monit 2020;26:e923549.

12 Liu C-Y, Yang Y-Z, Zhang X-M, et al. The prevalence and influencing factors in anxiety in medical workers fighting COVID-19 in China: a cross-sectional survey. Epidemiol Infect 2020;148:e98.

13 Zhu Z, Xu S, Wang H, et al. COVID-19 in Wuhan: sociodemographic characteristics and hospital support measures associated with the immediate psychological impact on healthcare workers. EClinicalMedicine 2020;24:100443.

14 Lai J, Ma S, Wang Y, et al. Factors associated with mental health outcomes among health care workers exposed to coronavirus disease 2019. JAMA Netw Open 2020;3:e203976.

15 Gomez S, Anderson BJ, Yu H, et al. Benchmarking critical care wellbeing: before and after the coronavirus disease 2019 pandemic. Critical Care Explorations 2020;2:e0233.

16 Greenberg N, Docherty M, Gnanapragasam S, et al. Managing mental health challenges faced by healthcare workers during covid-19 pandemic. BMJ 2020;368:m1211.

17 Pappa S, Ntella V, Giannakas T, et al. Prevalence of depression, anxiety, and insomnia among healthcare workers during the COVID-19 pandemic: a systematic review and meta-analysis. Brain Behav Immun 2020;88:901-7.

18 World Health Organization, others. Mental health and psychosocial considerations during the COVID-19 outbreak, 18 March 2020. 2020. Geneva: World Health Organization, 2020.

19 Inter-Agency Standing Committee, others. Briefing note on addressing mental health and psychosocial aspects of COVID-19 OutbreakVersion 1.12020.

20 International Federation of Red Cross and Red Crescent Societies. Mental health and psychosocial support for staff, volunteers and communities in an outbreak of novel coronavirus 2020.

21 Koh Y, Hegney DG, Drury V. Comprehensive systematic review of healthcare workers' perceptions of risk and use of coping strategies towards emerging respiratory infectious diseases. Int J Evid Based Healthc 2011;9:403-19.

22 Robertson L, O'Toole J, Evans N. Historical context: SARS, MERS, and Ebola [Internet]. COVID-19 pandemic: a world in turmoil, 2020. Available: https://www.atrainceu.com/content/8-historical-contextsars-mers-and-ebola

23 Munn Z, Peters MDJ, Stern C, et al. Systematic review or scoping review? guidance for authors when choosing between a systematic or scoping review approach. BMC Med Res Methodol 2018;18:143.

24 Peters MDJ, Godfrey CM, Khalil H, et al. Guidance for conducting systematic scoping reviews. Int J Evid Based Healthc 2015;13:141-6.

25 Peters MDJ, Godfrey C, Mclnerney P. Chapter 11: Scoping reviews (2020 version). In: JBI manual for evidence synthesis. Adelaide: JBI, 2020. https://synthesismanual.jbi.global

26 Arksey H, O'Malley L. Scoping studies: towards a methodological framework. Int J Soc Res Methodol 2005;8:19-32.

27 Levac D, Colquhoun H, O'Brien KK. Scoping studies: advancing the methodology. Implementation Science 2010;5:69.

28 Tricco AC, Lillie E, Zarin W, et al. PRISMA extension for scoping reviews (PRISMA-ScR): checklist and explanation. Ann Intern Med 2018;169:467-73

29 Segen's Medical Dictionary. Healthcare professional. The free dictionary, 2011. Available: https://medical-dictionary. thefreedictionary.com/healthcare+professional

30 Zautra AJ, Hall JS, Murray KE. Resilience: a new definition of health for people and communities. In: Reich JW, Zautra AJ, Hall JS, eds. Handbook of adult resilience. New York: The Guilford Press, 2010: 3-29. 
31 Foster K, Roche M, Delgado C, et al. Resilience and mental health nursing: an integrative review of international literature. Int J Ment Health Nurs 2019;28:71-85.

32 Robertson HD, Elliott AM, Burton C, et al. Resilience of primary healthcare professionals: a systematic review. Br J Gen Pract 2016;66:e423-33.

33 Matheson C, Robertson HD, Elliott AM, et al. Resilience of primary healthcare professionals working in challenging environments: a focus group study. Br J Gen Pract 2016;66:e507-15.

34 Speroni KG, Seibert DJ, Mallinson RK. Us nurses' perceptions regarding caring for suspected, probable, and confirmed Ebola virus disease patients, part 1: a quantitative analysis. J Nurs Adm 2015;45:477-84.

35 Speroni KG, Seibert DJ, Mallinson RK. Nurses' perceptions on Ebola care in the United States, part 2: a qualitative analysis. J Nurs Adm 2015;45:544-50.

36 Wu P, Liu X, Fang Y, et al. Alcohol abuse/dependence symptoms among hospital employees exposed to a SARS outbreak. Alcohol Alcohol 2008;43:706-12.

37 World Health Organization, others. Coronavirus disease (COVID-19) outbreak: rights, roles and responsibilities of health workers, including key considerations for occupational safety and health. World Health Organization, interim guidance, 2020. Available: https://www.who.int/publications/i/item/coronavirus-disease-( covid-19)-outbreak-rights-roles-and-responsibilities-of-healthworkers-including-key-considerations-for-occupational-safetyand-health

38 Medecins sans Frontieres. Stress and psychosocial well-being 2006.

39 Belfroid E, van Steenbergen J, Timen A, et al. Preparedness and the importance of meeting the needs of healthcare workers: a qualitative study on Ebola. J Hosp Infect 2018;98:212-8.

40 Bell SA, Munro-Kramer ML, Eisenberg MC, et al. "Ebola kills generations": Qualitative discussions with Liberian healthcare providers. Midwifery 2017;45:44-9.

41 Carvalho E, Castro P, León E, et al. Multi-professional simulation and risk perception of health care workers caring for Ebola-infected patients. Nurs Crit Care 2019;24:256-62.

42 Chen C-S, Wu H-Y, Yang P, et al. Psychological distress of nurses in Taiwan who worked during the outbreak of SARS. Psychiatric Services 2005;56:76-9.

43 von Strauss E, Paillard-Borg S, Holmgren J, et al. Global nursing in an Ebola viral haemorrhagic fever outbreak: before, during and after deployment. Glob Health Action 2017;10:1371427.

44 Abolfotouh MA, AIQarni AA, Al-Ghamdi SM, et al. An assessment of the level of concern among hospital-based health-care workers regarding MERS outbreaks in Saudi Arabia. BMC Infect Dis 2017;17:4

$45 \mathrm{Li} \mathrm{Y,} \mathrm{Wang} \mathrm{H}$, Jin X-R, et al. Experiences and challenges in the health protection of medical teams in the Chinese Ebola treatment center, Liberia: a qualitative study. Infect Dis Poverty 2018;7:92.

46 Maunder R, Lancee W, Balderson K, et al. Long-term psychological and occupational effects of providing Hospital healthcare during SARS outbreak. Emerg Infect Dis 2006;12:1924-32.

47 Wong TW, Yau JKY, Chan CLW, et al. The psychological impact of severe acute respiratory syndrome outbreak on healthcare workers in emergency departments and how they cope. Eur J Emerg Med 2005;12:13-18.

48 Andertun S, Hörnsten Åsa, Hajdarevic S. Ebola virus disease: caring for patients in Sierra Leone - a qualitative study. J Adv Nurs 2017;73:643-52.

49 Marrs R, Horsley TL, Hackbarth D, et al. High consequence infectious diseases training using interprofessional simulation and TeamSTEPPS. Am J Infect Control 2020;48:615-20.

50 World Health Organization, others. Occupational safety and health in public health emergencies: a manual for protecting health workers and responders. Geneva: ILO, 2018.

51 Al Ghobain M, Aldrees T, Alenezi A, et al. Perception and attitude of emergency room resident physicians toward middle East respiratory syndrome outbreak. Emerg Med Int 2017;2017:1-4.

52 O'Sullivan TL, Amaratunga C, Phillips KP, et al. If schools are closed, who will watch our kids? family caregiving and other sources of role conflict among nurses during large-scale outbreaks. Prehosp Disaster Med 2009;24:321-5.

53 Ministerie van Defensie. Militaire Geestelijke Gezondheidszorg. Tips \& adviezen voor de mentale gezondheid van zorgprofessionals, 2020. Available: https://www.defensie.nl/downloads/publicaties/ 2020/03/23/tips-en-adviezen-voor-mentale-gezondheidzorgprofessionals

54 Lehmann M, Bruenahl CA, Addo MM, et al. Acute Ebola virus disease patient treatment and health-related quality of life in health care professionals: a controlled study. J Psychosom Res 2016;83:69-74.

55 Al-Dorzi HM, Aldawood AS, Khan R, et al. The critical care response to a hospital outbreak of middle East respiratory syndrome coronavirus (MERS-CoV) infection: an observational study. Ann Intensive Care 2016;6.

56 Chan SSC, Leung GM, Tiwari AFY, et al. The impact of work-related risk on nurses during the SARS outbreak in Hong Kong. Fam Community Health 2005;28:274-87.

57 Kang HS, Son YD, Chae S-M, et al. Working experiences of nurses during the middle East respiratory syndrome outbreak. Int J Nurs Pract 2018;24:e12664-8.

58 Raven J, Wurie H, Witter S. Health workers' experiences of coping with the Ebola epidemic in Sierra Leone's health system: a qualitative study. BMC Health Serv Res 2018;18:251.

59 Styra R, Hawryluck L, Robinson S, et al. Impact on health care workers employed in high-risk areas during the Toronto SARS outbreak. J Psychosom Res 2008;64:177-83.

60 Tolomiczenko GS, Kahan M, Ricci M, et al. Sars: coping with the impact at a community hospital. J Adv Nurs 2005;50:101-10.

61 Bai Y, Lin C-C, Lin C-Y, et al. Survey of stress reactions among health care workers involved with the SARS outbreak. Psychiatric Services 2004;55:1055-7.

62 Chan AOM, Huak CY. Psychological impact of the 2003 severe acute respiratory syndrome outbreak on health care workers in a medium size regional General Hospital in Singapore. Occup Med 2004;54:190-6

63 Kim JS, Choi JS. Factors influencing emergency nurses' burnout during an outbreak of middle east respiratory syndrome coronavirus in Korea. Asian Nurs Res 2016;10:295-9.

64 Lee S-H, Juang Y-Y, Su Y-J, et al. Facing SARS: psychological impacts on SARS team nurses and psychiatric services in a Taiwan General Hospital. Gen Hosp Psychiatry 2005;27:352-8.

65 Lu Y-C, Shu B-C, Chang Y-Y, et al. The mental health of hospital workers dealing with severe acute respiratory syndrome. Psychother Psychosom 2006;75:370-5.

66 Marjanovic Z, Greenglass ER, Coffey S. The relevance of psychosocial variables and working conditions in predicting nurses coping strategies during the SARS crisis: An online questionnaire survey. Int J Nurs Stud 2007;44:991-8.

67 Poon E, Liu KS, Cheong DL, et al. Impact of severe respiratory syndrome on anxiety levels of front-line health care workers. Hong Kong Med J 2004;10:325-30.

68 Son H, Lee WJ, Kim HS. Hospital workers's psychological resilience after the 2015 middle East respiratory syndrome outbreak. Social Behavior and Personality: An International Journal 2019;47:1-13.

69 Khalid I, Khalid TJ, Qabajah MR, et al. Healthcare workers emotions, perceived stressors and coping strategies during a MERS-CoV outbreak. Clin Med Res 2016;14:7-14.

70 Lin C-Y, Peng Y-C, Wu Y-H, et al. The psychological effect of severe acute respiratory syndrome on emergency department staff. Emerg Med J 2007;24:12-17.

71 Liu C, Wang H, Zhou L, et al. Sources and symptoms of stress among nurses in the first Chinese anti-Ebola medical team during the Sierra Leone aid mission: a qualitative study. Int J Nurs Sci 2019;6:187-91.

72 Tam CWC, Pang EPF, Lam LCW, CWC T, LCW L, et al. Severe acute respiratory syndrome (SARS) in Hong Kong in 2003: stress and psychological impact among frontline healthcare workers. Psychol Med 2004:34:1197-204.

73 Su T-P, Lien T-C, Yang C-Y, et al. Prevalence of psychiatric morbidity and psychological adaptation of the nurses in a structured SARS caring unit during outbreak: a prospective and periodic assessment study in Taiwan. J Psychiatr Res 2007;41:119-30.

74 Dai Y, Hu G, Xiong H. Psychological impact of the coronavirus disease 2019 (COVID-19) outbreak on healthcare workers in China. medRxiv 2020.

75 Chen R, Chou K-R, Huang Y-J, et al. Effects of a SARS prevention programme in Taiwan on nursing staff's anxiety, depression and sleep quality: A longitudinal survey. Int J Nurs Stud 2006;43:215-25.

76 Qi J, Xu J, Li B-Z, et al. The evaluation of sleep disturbances for Chinese frontline medical workers under the outbreak of COVID-19. Sleep Med 2020;72:1-4.

77 Chen N-H, Wang P-C, Hsieh M-J, et al. Impact of severe acute respiratory syndrome care on the general health status of healthcare workers in Taiwan. Infect Control Hosp Epidemiol 2007;28:75-9.

78 Bournes DA, Ferguson-Paré M. Persevering through a difficult time during the SARS outbreak in Toronto. Nurs Sci Q 2005;18:324-33.

79 Maunder R. The experience of the 2003 SARS outbreak as a traumatic stress among frontline healthcare workers in Toronto: lessons learned. Phil Trans R Soc Lond B 2004;359:1117-25. 
80 O'Boyle C, Robertson C, Secor-Turner M. Public health emergencies: nurses' recommendations for effective actions. Aaohn J 2006;54:347-53.

81 Sin SS, Huak CY. Psychological impact of the SARS outbreak on a Singaporean rehabilitation department.including commentary by Leong I, Thompson DR 2004;11:417-24.

82 Grace SL, Hershenfield K, Robertson E, et al. The occupational and psychosocial impact of SARS on academic physicians in three affected hospitals. Psychosomatics 2005;46:385-91.

83 Gearing RE, Saini M, McNeill T. Experiences and implications of social workers practicing in a pediatric hospital environment affected by SARS. Health Soc Work 2007;32:17-27.

84 Kim Y. Nurses' experiences of care for patients with Middle East respiratory syndrome-coronavirus in South Korea. Am J Infect Control 2018:46:781-7.

85 Smith MW, Smith PW, Kratochvil CJ, et al. The psychosocial challenges of caring for patients with Ebola virus disease. Health Secur 2017:15:104-9.

86 Huang L, Lei W, Xu F, et al. Emotional responses and coping strategies in nurses and nursing students during Covid-19 outbreak: a comparative study.. PLoS One 2020;15.

87 Jeong-Sil C, Ji-Soo K. Factors influencing emergency nurse's ethical problems during the outbreak of MERS-CoV. Nursing Ethics 2018;25:335-45.

88 Tomczyk D, Alvarez D, Borgman P, et al. Caring for those who care: the role of the occupational health nurse in disasters. $A A O H N J$ 2008;56:243-50.

89 Chen Q, Liang M, Li Y, et al. Mental health care for medical staff in China during the COVID-19 outbreak. Lancet Psychiatry 2020;7:e15-16.

90 Khee KS, Lee LB, Chai OT, et al. The psychological impact of SARS on health care providers 2004

91 Shih F-J, Turale S, Lin Y-S, et al. Surviving a life-threatening crisis: Taiwan's nurse leaders' reflections and difficulties fighting the SARS epidemic. J Clin Nurs 2009;18:3391-400.

92 Hand C, Letts L. Occupational therapy research and practice involving adults with chronic diseases: a scoping review and Internet scan. Ottawa: Canadian Association of Occupational Therapists, 2009.

93 Brien SE, Lorenzetti DL, Lewis S, et al. Overview of a formal scoping review on health system report cards. Implement Sci 2010;5:2.

94 Liang H, Acharya G. Novel corona virus disease (COVID-19) in pregnancy: what clinical recommendations to follow? Acta Obstet Gynecol Scand 2020;99:439-42.

95 Petrovski Beáta Éva, Lumi X, Znaor L, et al. Reorganize and survive-a recommendation for healthcare services affected by COVID-19-the ophthalmology experience. Eye 2020;34:1-3.

96 Poon LC, Yang H, Lee JCS, et al. ISUOG Interim Guidance on 2019 novel coronavirus infection during pregnancy and puerperium: information for healthcare professionals. Ultrasound Obstet Gynecol 2020;55:700-8.

97 Ornell F, Halpern SC, Kessler FHP, et al. The impact of the COVID-19 pandemic on the mental health of healthcare professionals. Cadernos de Saúde Pública 2020;36:e00063520.

98 Plomecka MB, Gobbi S, Neckels R. Mental health impact of COVID-19: a global study of risk and resilience factors. medRxiv 2020.

99 De Brier N, Stroobants S, Vandekerckhove P, et al. Factors affecting mental health of health care workers during coronavirus disease outbreaks (SARS, MERS \& COVID-19): a rapid systematic review. PLoS One 2020;15:e0244052.

100 Chew NWS, Lee GKH, Tan BYQ, et al. A multinational, multicentre study on the psychological outcomes and associated physical symptoms amongst healthcare workers during COVID-19 outbreak. Brain Behav Immun 2020;88:559-65.

101 Orrù G, Ciacchini R, Gemignani A, et al. Psychological intervention measures during the COVID-19 pandemic. Clinical Neuropsychiatry 2020:17:76-9

102 Shanafelt T, Ripp J, Trockel M. Understanding and addressing sources of anxiety among health care professionals during the COVID-19 pandemic. JAMA 2020;323:2133-4

103 Sasangohar F, Jones SL, Masud FN, et al. Provider burnout and fatigue during the COVID-19 pandemic: lessons learned from a high-volume intensive care unit. Anesth Analg 2020;131: 106-11.

104 Brandford AA, Reed DB. Depression in registered nurses: a state of the science. Workplace Health Saf 2016;64:488-511.

105 Letvak S, Ruhm CJ, McCoy T. Depression in Hospital-Employed nurses. Clinical Nurse Specialist 2012;26:177-82.

106 Theorell T, Hammarström A, Aronsson G, et al. A systematic review including meta-analysis of work environment and depressive symptoms. BMC Public Health 2015;15:738.

107 Witkoski A, Dickson VV. Hospital staff nurses' work hours, mea periods, and rest breaks. A review from an occupational health nurse perspective. Aaohn J 2010;58:489-97.

108 Trinkoff AM, Le R, Geiger-Brown J, et al. Work schedule, needle use, and needlestick injuries among registered nurses. Infect Control Hosp Epidemiol 2007;28:156-64.

109 Dababneh AJ, Swanson N, Shell RL. Impact of added rest breaks on the productivity and well being of workers. Ergonomics 2001;44:164-74.

110 Faucett J, Meyers J, Miles J, et al. Rest break interventions in stoop labor tasks. Appl Ergon 2007;38:219-26.

111 Galinsky TL, Swanson NG, Sauter SL, et al. A field study of supplementary rest breaks for data-entry operators. Ergonomics 2000;43:622-38.

112 Tucker P, Folkard S, Macdonald I. Rest breaks and accident risk. The Lancet 2003;361:680.

113 Fiksenbaum L, Marjanovic Z, Greenglass ER, et al. Emotional exhaustion and state anger in nurses who worked during the SARS outbreak: the role of perceived threat and organizational support. Can J Commun Ment Health 2006;25:89-103.

114 Bukhari EE, Temsah MH, Aleyadhy AA, et al. Middle East respiratory syndrome coronavirus (MERS-CoV) outbreak perceptions of risk and stress evaluation in nurses. $J$ Infect Dev Ctries 2016;10:845-50.

115 Hewlett BL, Hewlett BS. Providing care and facing death: nursing during Ebola outbreaks in central Africa. $J$ Transcult Nurs 2005;16:289-97.

116 Imai T, Takahashi K, Hasegawa N, et al. Sars risk perceptions in healthcare workers, Japan. Emerg Infect Dis 2005;11:404-14.

117 Yiwen K, Hegney D, Drury V. A comprehensive systematic review of healthcare workers' perceptions of risk from exposure to emerging acute respiratory infectious diseases and the perceived effectiveness of strategies used to facilitate healthy coping in acute hospital and community healthcare settings. JBI Libr Syst Rev;8:917-71.

118 Liu X, Kakade M, Fuller CJ, et al. Depression after exposure to stressful events: lessons learned from the severe acute respiratory syndrome epidemic. Compr Psychiatry 2012;53:15-23.

119 Rambaldini G, Wilson K, Rath D, et al. The impact of severe acute respiratory syndrome on medical house staff: a qualitative study. $J$ Gen Intern Med 2005;20:381-5.

120 Shih F-J, Gau M-L, Kao C-C, et al. Dying and caring on the edge: Taiwan's surviving nurses' reflections on taking care of patients with severe acute respiratory syndrome. Appl Nurs Res 2007;20:171-80. 